\title{
ИНСТИТУТ ЗАНЯТОСТИ В РАЗВИТИИ КАЧЕСТВА ТРУДОВОЙ ЖИЗНИ
}

\author{
(c) 2019 Сафина Лилия Моратовна \\ старший преподаватель кафедры финансовых рынков и финансовых институтов \\ Института управления, экономики и финансов \\ Казанский федеральный университет, Россия, Казань \\ E-mail: lilisafina1@gmail.com \\ (c) 2019 Валеев Эмиль Рамилевич
}

кандидат экономических наук, доцент кафедры управления человеческими ресурсами

Института управления, экономики и финансов

Казанский федеральный университет, Россия, Казань

(c) 2019 Карасик Елена Анатольевна

кандидат экономических наук, доцент кафедры управления человеческими ресурсами

Института управления, экономики и финансов

Казанский федеральный университет, Россия, Казань

В статье рассматривается институциональный аспект занятости в развитии качества трудовой жизни России. Выявлены факты влияния формальных и неформальных правил на формирование оппортунистического поведения субъектов института занятости и возможные пути их преодоления.

Ключевые слова: качество жизни, качество трудовой жизни, институт занятости

В современной институциональной теории одним из фундаментальных понятий является понятие института, опирающееся на нормы и (или) правила, формализующие особенности социально-экономического взаимодействия субъектов. В своей работе «Институты, институциональные изменения и функционирование экономики», Норт Д. дает следующее определение: институт - это «правила игры» в обществе, или, выражаясь более формально, созданные человеком ограничительные рамки, которые организуют взаимодействия между людьми [3].

В работах по институциональной теории однозначно определяется фактор воздействия институтов, как на эффективность экономики, так и на экономический рост. Например, в исследовании сотрудников Мирового банка Ф. Кифера и М. Ширли [5]. был сделан вывод, что наибольшее влияние на экономический рост оказывают, формальные правила или институты, а государство контролируя их обеспечивает увеличение темпов экономического роста, снижение социальной напряженности и роста благосостояния общества.

В институциональной теории применяются различные подходы к описанию и классификации институтов. Наиболее известным методом является их разделение на две группы: фор- мальные институты (правила) и неформальные институты (правила). Под неформальными правилами понимаются некие ценностно-нормативные обязательства, поддерживаемые и применяемые во взаимоотношениях людей. Под формальными правилами понимаются установленные требования к организации взаимодействия людей в процессах коллективной деятельности, как утвержденные государством, так и уполномоченной структурой, признаваемой государством.

Очевидно, что формирование и развитие качества трудовой жизни (КТЖ) происходит под влиянием группы институтов. Если разделить, на наш взгляд, все институты КТЖ, то можно выделить регламентирующие, регулирующие и развивающие институты [4]. При этом подходе к классификации институтов КТЖ они сгруппированы таким образом, что каждая группа оказывает воздействие на формирование и развитие КТЖ не только на микроуровне (уровне отдельных структурных подразделений организации), но на уровне организации и общества в целом.

В общем случае каждый институт может быть охарактеризован как по типу номинального носителя института (например, трудоспособное население) и множеству субъектов данного типа (занятое население моложе трудоспособ- 
ного возраста, занятые предпенсионеры и т.п.), так и множеству фактических носителей института соблюдающих норму (занятые в формальном секторе предпенсионеры, занятые в неформальном секторе предпенсионеры, безработные предпенсионеры и т.п.). В общей сложности может использоваться 8-10 характеристик, определяющих различие в институтах [1].

Центральным объектом нашего исследования является институт занятости, относящейся в представленной классификации к регулирующим институтам. Этот институт, по нашему мнению, занимает одно из центральных мест в формировании базовых параметров КТЖ. При этом изменения, затрагивающие институт занятости, затрагивают количественные значения параметров, например уровень оплаты труда, количество пострадавших от несчастных случаев на производстве работников, уровень безработицы и др. Институт занятости определяет предметную область качества трудовой жизни, вектор ее развития.

С другой стороны, комплексная характеристика КТЖ включает в себя множество параметров субъективного характера, таких как удовлетворенность трудом, социальнопсихологическая атмосфера и др., что сложно оценить и измерить. С позиции КТЖ важно понимать занятость не только как показатель, характеризующий ситуацию на рынке труда, но и мотивы занятости. Очевидно, исходя из статистики занятости в неформальном секторе, что работники выбирают в каждом 5 случае такую ситуацию, что заведомо связана с низким или отсутствующим качеством в их трудовой деятельности, таблица 1.

Сохранение такой тенденции, когда фактически на протяжении последних 10 лет наблюдается рост неформальной занятости, требует исследования вопроса, что определяет эту практику на российском рынке, когда фактически все аспекты качества трудовой жизни низкие, а возможность защиты своих прав минимальна.

Институт занятости в развитии качества трудовой жизни занимает особое место. Понятие «контракта», регулирующего взаимоотношения работника и работодателя является ключевым положением института занятости. В рамках него определяются такие условия взаимодействия работника-работодателя как оклад, величина денежного довольствия и др, что связано с величиной заработной платы, режим работы и условия выполнения трудовых обязательств, меры социальной защиты и поддержки и т.д.

По определению А.А. Аузана, контракт можно рассматривать как совокупность правил, структурирующих в пространстве и во времени обмен между экономическими агентами путем определения обмениваемых прав и взятых обязательств, а также определения механизма их соблюдения. Таким образом, в рамках институциональной теории возможно успешное взаимодействие работника и работодателя по развитию КТЖ в случае если контракт (трудовой договор) приближен к классическому контракту, включающему все существенные аспекты взаимодействия работника и работодателя. Гарантом выполнения контракта должны выступать регламентирующие институты государства по защите прав занятых.

В реальных условиях трудовой договор не является классическим контрактом. Несовершенство контрактных отношений связано с неполнотой контрактов: в реальности, при нарушении условий такого соглашения, формально прописанных, не может осуществляться только правовыми методами. Так как стороны контракта не способны предвидеть все варианты изменения обстоятельств из-за разнообразия комбинаций, то контрагенты имеют возможность продемонстрировать оппортунистическое поведение для достижения собственных целей. Например, невозможно зафиксировать в письменном виде все пункты трудовых отношений как долговременные. В этих условиях выбирается вариант сотрудничества с обозримым сроком и персонализированный подход в каждом конкретном случае. Фактором, способствующим оппортунистическому поведению, является проблема взаимодействия принципала и агента. Принципал - это сторона, предлагающая контракт, а агент - это сторона, наделенная правом принятия решения по контракту. Агент, в данном случае работодатель, может прибегать к оп-

Таблица 1. Уровень неформальной занятости в России,\% [1]

\begin{tabular}{|c|c|c|c|c|}
\hline Годы & $\mathbf{2 0 1 5}$ & $\mathbf{2 0 1 6}$ & $\mathbf{2 0 1 7}$ & $\mathbf{2 0 1 8}$ \\
\hline Всего & 20,5 & 21,2 & 19,8 & 20,1 \\
\hline
\end{tabular}


портунистическому поведению для реализации собственных интересов ввиду того, что принципал ограничен в полном контроле его действий.

На наш взгляд, существующая асимметрия информации, является в первую очередь фактором возникновения оппортунистического поведения. Имеющая информационное преимущество сторона - работодатель, обладает возможностью уклоняться от контрактных обязательств, наглядно демонстрируя оппортунистическое поведение. Например, увольнение работника по механизму сокращения штата, тогда как фактически штатная единица выводится только на время, а на его место принимается «свой» человек.

При рассмотрении аспектов формирования оппортунистического поведения субъектов института занятости, важным является вопрос определения соотношения формальных и неформальных правил. Выделяют следующие ситуации соотношения формальных и неформальных правил: во-первых, это ситуация, когда формальное правило вводится на базе позитивно проявившего себя неформального правила. В качестве примера в вопросах занятости можно рассмотреть процесс формализация норм права рекомендованных профессиональными сообществами, профсоюзами (например, сокращение рабочего времени в предпраздничные дни); они приобретали норму закона при включении в Трудовой кодекс РФ.

Во-вторых, это ситуация, когда формальное правило вводится для противодействия сложившимся неформальным нормам. При негативной оценке неформальных норм со стороны государства выстраивается система противодействия или механизма принуждения. В сфере решения социально-трудовых конфликтов в качестве примера можно рассмотреть введение законодательных норм в России ограничивающих протестные выступления и пикеты по всему спектру вопросов, включая трудовые споры путем ужесточения наказания.

В-третьих, это ситуация, когда неформальные правила вытесняют формальные. Это происходит в случае роста неоправданных издержек у их субъектов, не приносящих ощутимых выгод ни государству, ни гарантам таких правил. В качестве примера можно рассмотреть практику решения судебных споров при прецедентной системе права. Такая система демонстрирует большую гибкость, стабильность и учет нюансов правоприменения. При рассмотрении дела приоритет сохраняется за современными нормами.

B-четвертых, это ситуация, когда возникающие в обществе неформальные правила способствуют реализации существующих формальных правил. В качестве примера мы можем рассмотреть нормы взаимоотношений в организации в рамках существующей культуры, фактически возникающей вокруг формальных правил, прописываемых, в том числе и в трудовом соглашении (например, дресскод).

Нужно отметить, что при изучении социально-трудовых отношений на российских предприятиях в условиях сложившейся институциональной среды фиксируется преобладание неформальных правил в регулировании взаимоотношений между работником и работодателем [3].

В результате при рассмотрении соотношения формальных и неформальных правил в системе формирования и развития КТЖ организации можно выделить особый пятый вид ситуации, когда формальные правила существуют параллельно неформальным правилам. Особые условия хозяйствования в России, сложившиеся за годы преобразований, показали, что важным условием для выживания становится функционирование организации в формате закрытого института.

Несовершенство бизнес-климата в части защиты прав собственности определяет политику руководства организаций по созданию некой «изоляционной оболочки» организации. Она появляется в результате сращивания структур власти и бизнеса, когда институты, призванные осуществлять контроль, не вмешиваются в деятельность отдельных организаций по указанию «сверху». Таким образом, складывается ситуация, когда для снижения издержек, на взгляд стороннего наблюдателя, организации выполняют существующие формальные правила, однако внутри них определяющее значение играют «свои правила игры», т.е. доминируют неформальные правила, транслируемые, в первую очередь, руководством организации. Примером такого параллельного существования правил, влияющих на КТЖ, являются правила определения режима занятости. Формально целый ряд законодательных и нормативных актов РФ, определяют, даже гарантируют занятость для отдельных категорий занятых, таких как предпенсионеры, инвалиды. Однако на практике в самой организации заня- 
тость определяется неформальными правилами. К ним можно отнести практику одновременного написания заявления на увольнение с открытой датой в момент приема на работу, практику оформления неполной занятости, тогда как по факту занятость полная (это позволяет работодателю на «законных» основаниях устанавливать официальную зарплату меньше МРОТ) или предложение «оформиться без договора» и т.п.

Еще одним примером двойного стандарта, как существования, так и применения правил, являются правила в области трудовой дисциплины, формально фиксируемые во внутренних документах, приказах. При этом правила, касающиеся дисциплины в организациях, являются гибкими и зависят от интерпретации конкретного руководителя по отношению к конкретному работнику. Российская практика демонстрирует, в частности, широкое использование системы штрафов. Ни Трудовой кодекс РФ, ни иные нормативно-правовые акты не предусматривают такой меры дисциплинарного взыскания. При этом формальные правила существуют и могут быть также использованы.

На наш взгляд, именно ситуация параллельного существования формальных и неформальных правил института занятости обуславливает общий низкий уровень КТЖ на российских предприятиях, возможность уклонения от контрактных обязательств.

Именно потому, что трудовые контракты, определяющие занятость не должны быть подвержены разночтениям, интерпретациям и манипуляциям со стороны работодателей, склонных к оппортунистическому поведению, они нуждаются в защите. При этом чрезвычайно важно, чтобы часть таких регулятивных мер не навязывалась участникам экономических взаимодействий извне, а вырабатывалась по обоюдному согласию, исходя из их собственных возможностей и защиты интересов в суде. В этом случае можно рассчитывать, что институт занятости будет определять как развитие качества трудовой жизни, так и рост качества жизни в российском обществе.

\section{Библиографический список}

1. Индикаторы достойного труда. [Электронный ресурс] URL: https://www.gks.ru/labor_market_employment_ salaries (дата обращения 20.11.2019)

2. Клейнер Г.Б. Институты: определение, признаки и направления исследования // Управление.2016. - № 3(13).- С. 5-11

3. Норт Д. Институты, институциональные изменения и функционирование экономики. - М.: Начала, 1997.С. 17

4. Сафина Л.М. Институты формирования и развития качества трудовой жизни // Казанский экономический вестник. -2013. - № 1.- С. 55-58

5. Keefer, Philip and Shirley, Mary M. From the Ivory Tower to the Corridors of Power: Making Institutions Matter for Development Policy? Mimeo, World Bank., 1998. 